\title{
Contribution to the validation of the conceptual model of the global satisfaction of the users in the Portuguese military health services
}

\begin{abstract}
Introduction: Patient satisfaction is an important measure in assessing the performance of public health systems. However, at the level of Portuguese military health services, studies that assess user satisfaction are limited. To this end, the global satisfaction evaluation model is widely used and it seems to gather consensus among the international scientific community, but studies that determine its validity in the users of the Portuguese military health services are not known.
\end{abstract}

Objectives: In 2016, it was tried to determine the validity of the conceptualization model of the European version of the global satisfaction of the users, as well as to evaluate the satisfaction index of the users, within the health service of the School of Arms of the Portuguese Army.

Method: In December 2016, according to a cross-sectional observational study, a sample of 262 patients was assessed using the European Customer Satisfaction Index. Data analysis was performed using structural equations.

Results: With regard to the evaluation of the proposed model, there was an index of goodness of adjustment of 0.815 . Model was able to explain about $83.7 \%$ of the observations and a degree of representation for most of the observed variables (adjusted $\mathrm{R}^{2}$ ) between 0.3 e 0.9 . It was also found that the size of the effect of latent variables on the explanation of another latent variable $\left(\mathrm{F}^{2}\right)$ was greater than 0.35 . It was also determined, with $95 \%$ certainty and type I error probability of 0.0000 , an average of satisfaction of users of 6.8 values.

Discussion: The evaluation of the quality of the proposed model suggests that the results obtained are robust and representative of the study population. With a margin of error of $5 \%$, it was also verified that the global satisfaction index obtained is high.

Conclusion: The proposed model of user satisfaction assessment is globally valid and adequate to the context of the School of Arms health services. Already the global satisfaction index of users seems to follow the trend observed in public health services in Portugal.

Keywords: user satisfaction, health administration, military health services, portuguese army
Volume 7 Issue 3 - 2018

\author{
Pedro Miguel Alves Ribeiro Correia,' Ana \\ Teresa Nogueira Jeremias, ${ }^{2}$ Vitor Manuel dos \\ Santos Camocho ${ }^{3}$ \\ 'CAPP, ISCSP, University of Lisbon, Portugal \\ ${ }^{2}$ School of Health of the Polytechnic Institute of Setúbal, \\ Portugal \\ ${ }^{3}$ School of Military Health Service, Portugal
}

Correspondence: Pedro Miguel Alves Ribeiro Correia Higher Institute of Social and Political Sciences, Rua Almerindo Lessa-1300-663 Lisbon, Portugal, Consultant of the Directorate General of Justice Policy (DGPJ) of the Ministry of Justice of Portugal, Tel +35I-96-4I4-76-7I

Email pcorreia@iscsp.ulisboa.pt

Received: December II, 2017| Published: June 28, 2018

\section{Introduction}

\section{Contextualization}

At present, it is recognized that in order to evaluate and strengthen the performance of public systems, where the Portuguese military health system can be placed, one should not rely solely on their own knowledge and insights. ${ }^{1}$ It is recommended that a citizen-centered approach to public administration be adopted, ${ }^{1,2}$ in which emphasis is given to values such as customer care, user valorisation and valorisation in meeting the needs of the user. Associated with the private context. ${ }^{3,4}$ According to this, it is accepted that the contact with the services allows the citizen to develop a judgment of the performance of the same ones. ${ }^{5-9}$, The confrontation between their initial expectations and their realization results in a perception of satisfaction. ${ }^{8}$ In other words, user satisfaction contributes to assessing the ability of services (in view of their characteristics) to satisfy citizens. ${ }^{1,9}$ This is why an increasingly used parameter, which, by contributing to the identification of the factors that influence the satisfaction of the user, allows directing adaptations in the provision of health services, and thus enhancing the quality of health services. ${ }^{10,11}$

\section{Paradigm associated with user satisfaction}

The model of evaluation of the global satisfaction proposed by Fornell et al. ${ }^{12}$ embodied by the American Customer Satisfaction Index (ACSI), adapted for Europe as the European Customer Satisfaction Index (ECSI) ${ }^{13}$ and adopted in Portugal ${ }^{14}$, seems to reflect the conceptualization of the global satisfaction of the users that more consensus gathers by the scientific community, being widely used in several public and private services throughout the world. This model considers that the satisfaction dimension is uniform, comparable and measurable through a methodology based on two assumptions: $1^{\circ}$. The result of "satisfaction" comes from the interdependence of a set of factors and the extent to which this influence occurs is variable between people; $2^{\circ}$. The satisfaction index is considered a global measure. These aspects contribute to the "satisfaction" dimension being central to a chain of previous relationships, such as user "expectations", "value" and "quality" perceived or subsequent to user satisfaction, such as "complaints" and finally "loyalty".,12-14 Given the satisfaction model described, its wide use and the specificity of the context of the current military services, it is questioned whether the aforementioned model will be valid to evaluate the global satisfaction 
of Portuguese military health services and what will be the global satisfaction of the users of army health units in Portugal.

\section{Literature review}

In Portugal as in the rest of the world, in order to determine the level of satisfaction of its clients, some studies have been carried out on users satisfaction ${ }^{13}$ in sectors such as health services (telecommunications), telecommunications, passenger transport, banking, insurance, communications, fuels, gas in the bottle, natural gas, electricity, dual (2005), and in the literature on the use of water, passenger and water ${ }^{10,15,16}$ in many of these cases, the importance of evaluating the overall rate of users satisfaction has been reinforced in order to assess and enhance the performance of public services in terms of quality, responsiveness and sustainability ${ }^{8,916,17}$ and prioritization of services to meet the needs of citizens. ${ }^{1,916}$ In addition, some of these studies have analyzed the validity of the ${ }^{12}$ construct such as that of ${ }^{13}$ in which evidence was obtained suggesting changes to the initial model, since they did not find significant influence of expectations on customer satisfaction, as well as expectations about perceived value. These results raise doubts regarding the construct of the customer satisfaction model of Fornell et al. ${ }^{12}$ In addition, the authors compared ACSI and ECSI suggesting that ECSI can measure satisfaction less accurately than ACSI. Also, Revilla-Camachoa et al. ${ }^{18}$ obtained data that do not support all presumed relationships in the initial model, such as the influence of perceived quality on customer satisfaction or the influence of claims on loyalty. In both studies, the authors recommend further studies to ascertain the consistency of these clues.

In Portugal, although this is one of the measures most used by companies to determine the overall customer satisfaction index, ${ }^{14}$ few studies have been devoted to analyzing the construct of the aforementioned model translated by the European version. The research carried out by Ferreira et al., ${ }^{19}$ at the level of the Portuguese mold industry, is also worthy of note. This results in increasing doubts about the construct of the model, since, for example, there was no significant influence of perceived value on satisfaction. In the context of the Portuguese military health services, this study seems to be even more important since specificities are reconnoitred that may lead to differences in the weight of determinants of satisfaction in the final results when compared to other contexts..$^{20,21}$ In addition, in the context of the military health services, there is a lack of studies that examine the perspective of the users, namely their global satisfaction index, which supports a continuous evaluation and even a possible restructuring of the same in order to correspond to the real ones interests and needs of its users. ${ }^{8,10}$ The present study aims to contribute to the minimization of the identified gaps and needs, aiming to determine the validity of the ${ }^{12}$ model translated by ECSI and to evaluate the global satisfaction index of the users perceived by the users when using the health services of the School of Arms in December 2016.

\section{Methods}

\section{Data collection}

Ethical aspects: In order to guarantee ethical rights, ${ }^{22}$ by means of an explanatory letter, all persons had access to information related to the study, including scope, objectives, procedures for data collection and analysis. They were also given the electronic contact of the person in charge of the study to enable the clarification of additional doubts. After properly clarified, and by completing an informed consent, the right of decision of the persons to participate or not in the study was safeguarded, without any consequence. Finally, the confidentiality of the data was guaranteed, as no information was collected to identify the participants, and in the end, after analyzing the data, they were all eliminated.

Authorization procedures and period of data collection: In December 2016, the Chief of State of the Army and the Commander of the School of Arms permitted the collection of data from the participants and their use for scientific purposes. During the same month (December 5 to 31 ), through the professional email, the study began to be disseminated and data were collected simultaneously by providing the access link to the information platform with explanatory letter, informed consent and instrument of data collection.

Sampling method: A consecutive accidental recruitment process was used. $^{22}$

Factors of inclusion and exclusion: The people to be included in the study would have to be civilian or military, accepting all professional ties, specialties, weapons or services. They could be studying, in active, in reserve or retired. They would have to be able to read and write, since the questionnaires are self-filled. Finally, individuals would have to authorize their participation through the completion of the informed consent document. On the other hand, the criteria defined for exclusion of data from participants were the failure of some inclusion factor and gaps in the filling of the data collection instrument.

Data collection instrument: Each participant completed the European Customer Satisfaction Index (ECSI), which, according to a structural equation analysis model (Figure 1), allows the determination of the overall satisfaction index (exit). ${ }^{1316}$ This instrument is widely recommended and used worldwide for its simplicity, low cost, reliability and sensitivity. ${ }^{12,13,16}$

The ECSI considers seven latent variables, whose characteristics do not allow a direct evaluation. ${ }^{16,23}$ Each of them is then determined through the evaluation of a group of indicators quantified using Likert scales (in ascending order of valorization, all points are numbered, successively from 1 to 10 ), through the filling of the questionnaire by the users of the health unit. ${ }^{16}$ The analysis model is established by the set of causal relationships between the latent variables and the indicators. ${ }^{16}$ Each of the interactions gives rise to a hypothesis tested in this investigation (H1 to H12) (Figure 1). ${ }^{13}$ In this model of analysis, the "image" incorporates the associations that the users make with the health unit. ${ }^{16}$ Theoretically, this variable has repercussions on "loyalty" (H1), "satisfaction" (H2) and "expectations" (H3). ${ }^{13}$ The "expectations" take into account the information that the users previously had about the health services available at the School of Arms (based on self-experience and third-party information)..$^{16}$ And the prospect about the capacity of the unit to offer quality services in the future (ECSI Portugal, 2016).${ }^{16}$ It is assumed that expectations are directly related to "perceived value" (H4), "perceived quality" (H5) and "satisfaction" of users (H6). ${ }^{13}$

The "quality perceived" by the users, understands its generic judgment and presupposes an evaluation based on the influence of several factors. ${ }^{16}$ It is believed that "perceived quality" has a direct influence on "satisfaction" (H7) and "perceived value" (H8). ${ }^{13}$ The "value perceived" appears to be cost-quality, being determined by the assessment of the users about the quality of the services, taking into account that they are free, and the evaluation of the absence 
of payment, given the quality of services. ${ }^{16}$ It is assumed that the "perceived value" has direct repercussions on the "satisfaction" of the users (H9). ${ }^{13}$ The model also refers to two performance indicators of the satisfaction index: ${ }^{13,16}$ "Loyalty" which is one of the most important indicators to allow an immediate relationship with the productivity of the service. ${ }^{16}$ It is assumed that the increase in the "loyalty" index is a direct consequence of the "satisfaction" of the user (H11). ${ }^{13,16}$ The other result of "satisfaction" is the treatment of "complaints" (H10), whose premise is that unsatisfied users are more likely to submit complaints than satisfied users. ${ }^{16}$ It is also envisaged that complaints will manifest themselves in the opposite way to loyalty (H12). ${ }^{13}$

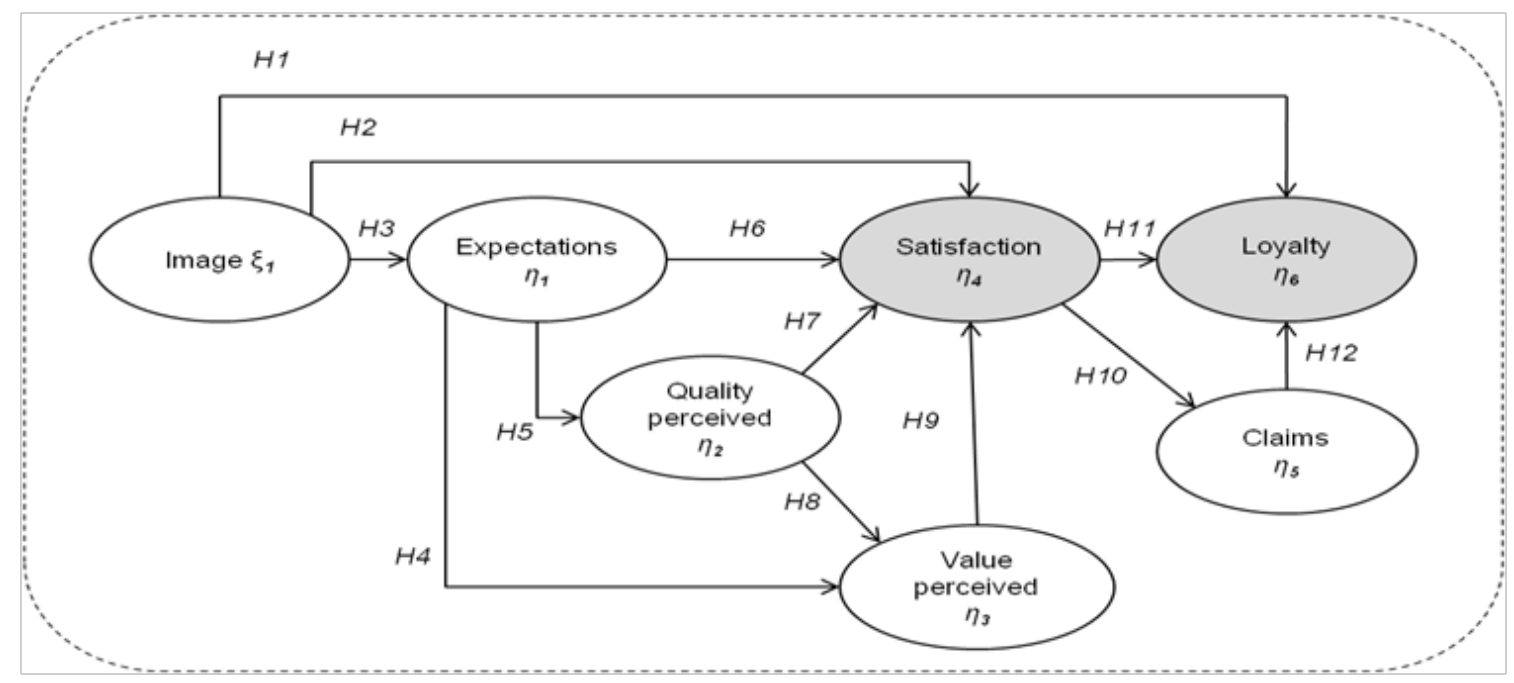

Figure I Global Satisfaction Evaluation Model.

Source:Adapted by the authors based on the scheme of ECSI Portugal. ${ }^{16}$

\section{Statistical analysis}

After completing the data collection process, the data were analyzed using the SPSS statistical software program, version 25, which included descriptive statistics calculations for the characterization of the sample. ${ }^{24}$ Finally, to estimate the user satisfaction model, ${ }^{23}$ structural equation analysis was performed using SPAD software, version $6.5{ }^{23}$ It is suggested that the use of this approach allows the study of latent variables and their causal interrelations, validating the data obtained without a direct evaluation (due to its impossibility), in view of the abstract characteristics of the variables..$^{23,25}$ The use of this analysis may also represent an increase of precision of the results by about $22 \%$, when compared with others. ${ }^{14,16}$

\section{Results}

\section{Sample characterization}

The present study considered a population of 623 people, who in December were at the School of Arms, and therefore, could enjoy their health service. From this, 302 people were selected, 37 of whom were excluded because they did not consent to participate in the study and another three were excluded due to failures in filling out the measurement instrument. At the end of the process, 262 users were included, forming the study sample, thus translating a $42.05 \%$ questionnaire response rate. ${ }^{24}$ As to baseline characteristics, it was verified that the mean age was 26years old, a predominantly male gender $(79.4 \%)$, in which the most frequent academic degree was secondary $(53.1 \%)$ and soon after graduation $(20.2 \%)$. The majority of the participants were military, with more representation of the official class (34.4\%) and squares (31.3\%). As for health care, the users used mostly medical consultations (50.4\%), followed by physical therapy $(43.1 \%)$, followed by nursing care $(38.9 \%)$, and finally, health care were the least requested $(26.3 \%)$. It is also important to note that some of the participants $(6.9 \%)$ stated that they have simultaneously taken care of lifeguards, nursing, physiotherapy and medicine.

\section{Global satisfaction index}

Overall, with a confidence level of $95 \%$ and $p$ value of 0.000 , the overall satisfaction index obtained was 6.8 values.

\section{Model of structural equations}

By analyzing the theoretical model proposed initially (Table I), the overall satisfaction index of the users can be clarified by the results of the averages, obtained in the evaluations of the latent variables (Figure 2): "image" 7.2 (CI 95\%; p value $=0.0000$ ); "expectations" 6.8 (CI 95\%; p value=0.0000); "perceived quality"” 6.9 (CI 95\%; $\mathrm{p}$ value $=0.0000)$; "perceived value" 7.5 (CI 95\%; p value $=0.0000)$; "satisfaction" 6.8 (CI 95\%; p value=0.0000); "claims" 6.6 (CI 95\%; $\mathrm{p}$ value $=0.0000)$; e "loyalty" 7.1 pontos (CI 95\%; p value $=0.0000$ ). As can be seen, the results obtained vary between mean values of 6.6 (claims) and 7.5 (perceived value), thus highlighting a positive and high perception in all dimensions. It should also be noted that the highest-rated indicators were in descending order: "Health unit represents a positive contribution to the Society" (7.82); "Satisfaction level attributed to the quality of health unit services, taking into account access to them" (7.59); "Health unit that cares about users" (7.45); "Satisfaction level attributed to the quality of the health unit's services, given that access to them is free" (7.44); "Sensitivity that access to the unit's health services is free" (7.44). It is still possible to observe the indicators with lower averages, having been in 
ascending order: "Accessibility to health unit services through new technologies" (6.13); "Innovative and forward-looking health unit"
(6.30); "Comparison of the health unit with the ideal health unit" (6.37); "Diversity of health unit services" (6.39).

\section{Table I Analysis Model}

Conceptualization ${ }^{13}$

Definition
institution's external

Indicators

The health unit is reliable in what it says and what it does.

The health unit is stable and established in the Public Administration.

Health Unit represents a positive contribution to the Society.

Health unit that cares about users.

Innovative and forward-looking health unit.

Global Expectations about Unity.

Expectations about the capacity of the health unit, to offer services that meet the needs of the users. user expected to receive from the service and what he actually received. ${ }^{12,13}$

Evaluation that the user makes of the service based on two factors: consumption and reliability. ${ }^{12,13}$

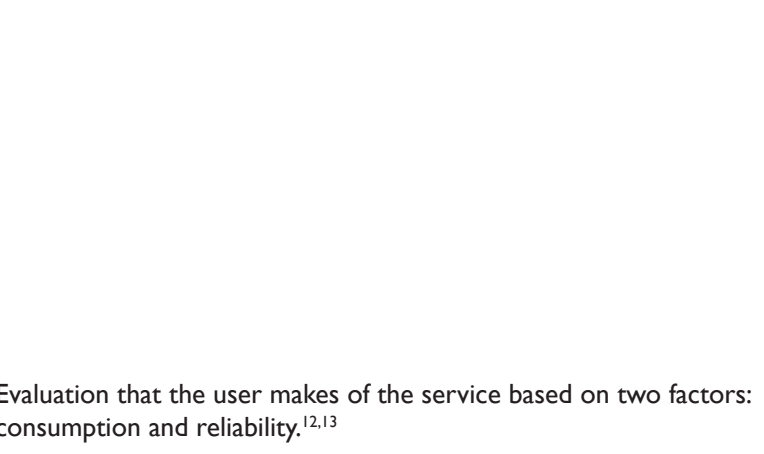

\author{
Expectations regarding reliability, that is, how often \\ things go well. \\ Overall quality of the health unit. \\ Quality of health unit services.
}

Attendance and counseling capacity in the health unit.

Accessibility of health unit services through new technologies.

Reliability of health unit services.

Diversity of health unit services.

Clarity and transparency of the information provided by the health unit.

Availability / location / accessibility to health facility facilities.

Level of satisfaction for access is free, given the quality that the health unit services believe.

Satisfaction level attributed to the quality of the health unit's services, given that access to them is free. 


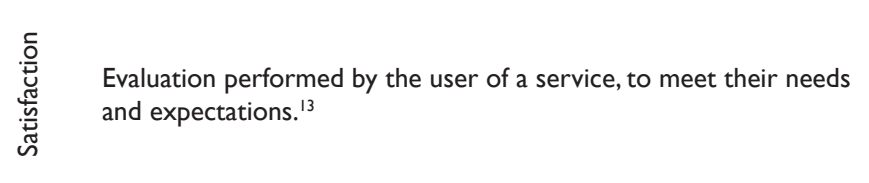

$\frac{E^{\frac{\omega}{U}}}{U}$ Result of user dissatisfaction with a service. ${ }^{13}$

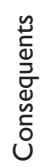

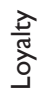

The consequence of several interactions between the parties, in which the user acquires confidence in the services enjoyed. Can be defined as a behavioral intent related to the service provided. ${ }^{12,13}$
Overall satisfaction with the health unit.

Satisfaction compared to expectations (achievement of expectations) about the health unit.

Comparison of the health unit with the "ideal health unit".

(For those who complained) How the last complaint to the health unit was resolved.

(For those who did not complain) Perception about how complaints would be resolved at the health facility.

Sensitivity relating to the fact that access to the unit's health services is free.

Probability of recommending the unit to colleagues and friends.

Source: adapted by the authors of ECSI Portugal ${ }^{14}$ and Lopes, et al..$^{13}$

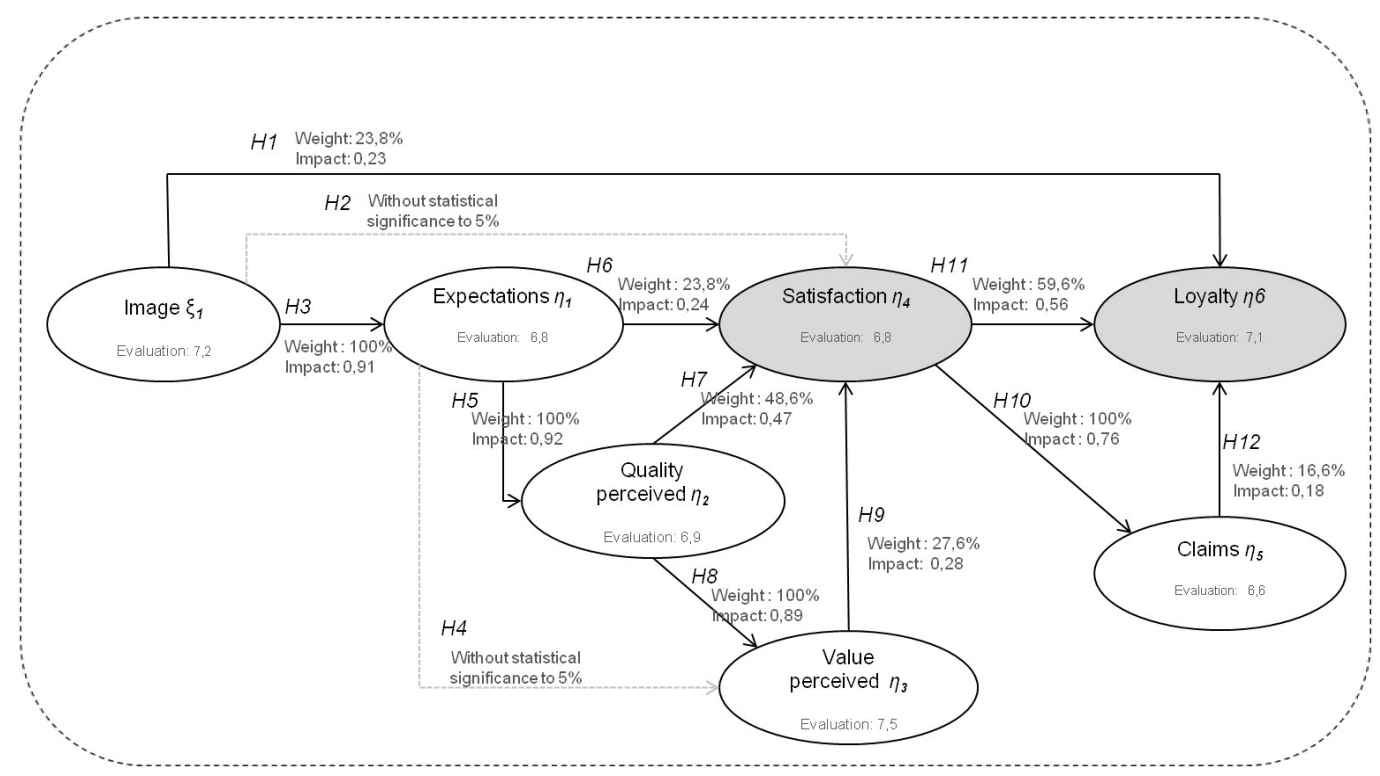

Figure 2 Results Relating to the Global Satisfaction Assessment Model.

Source:Adapted by the authors based on the scheme of ECSI Portugal ${ }^{16}$ and the results of the present study.

As shown in Figure 2, with a confidence level of $95 \%$ and a probability of error of 0.0000 , it was observed that:

i. The increase of 1 value in the average evaluation of the "image" variable represents a direct impact of 0.91 values in the dimension "expectations" (H3). Similarly, the increase of 1 in the average of the "expectations" of the users has an impact of 0.92 on "perceived quality" (H5);

ii. the increase of 1 value of the average "perceived quality" 
evaluation shows a $89 \%$ impact on the "perceived value" by the participants (H8);

iii. the "satisfaction" dimension, the average obtained is directly conditioned by the $23.8 \%$ increase in the average "expectations" (H6), $48.6 \%$ in the average "perceived quality" (H7) and 27.6\% in the average "Perceived value" (H9), with an impact on its final average of $0.24(\mathrm{H} 6), 0.47(\mathrm{H} 7)$ and $0.28(\mathrm{H} 9)$ respectively;

iv. The results related to the "satisfaction" variable have a direct influence on "complaints" (H10) and "loyalty" (H11). As an increase of 1 value has an impact of 0.76 on the average value reached in the dimension "claims" (H10) and with a weight of $59.6 \%$ causes an impact of 0.56 points in the final average of "loyalty" (H11);

v. The "loyalty" index also suffers an impact of 0.18 of the "complaints" whose demonstrated weight is $16.6 \%$ (H12). And about $23.8 \%$ of its average is explained by the influence of the "image" of the users, contributing to a maximum impact of 0.23 values $(\mathrm{H} 1)$.

According to Table 2, the proposed model presents a goodness index of the adjustment $(\mathrm{GoF})$ of 0.815 . It explains about $83.7 \%$ of the observations (mean of the mean $\mathrm{H}^{2}=0.8366$ ) and a degree of representation for the majority of the variables observed varying between 0.3 and 0.9 (adjusted $\mathrm{R}^{2}>0.3$ and $<0.9$ ), except for those that fall within the "claims, "in which approximately 0.58 were obtained. It was also verified that the size of the effect of the latent variables in the explanation of another variable suggests a redundancy $\left(\mathrm{F}^{2}\right)$ greater than 0.35 for all blocks and a mean (mean of the mean $\mathrm{F}^{2}$ ) redundancy of 0.6975 . A p-value of less than 0.000 among all causeeffect relationships studied (H1, H3, H5, H6, H7, H8, H9, H10, H11 and $\mathrm{H} 12$ with Proba $>|\mathrm{T}|=0.000$ ), with the exception of the "image" about "satisfaction" (H2) and "expectations" in "perceived value" (H4).

Table 2 Evaluation of the Structural Model.

\begin{tabular}{|c|c|c|c|c|c|c|}
\hline \multirow[t]{2}{*}{ Block } & \multirow[t]{2}{*}{ Mean } & \multirow[t]{2}{*}{$\begin{array}{l}\text { Rho dillon- } \\
\text { goldstein }\end{array}$} & \multirow[t]{2}{*}{ Adjusted R2 } & \multirow[t]{2}{*}{ GoF } & \multirow{2}{*}{$\begin{array}{l}\text { External quality of } \\
\text { the model } \\
\text { Mean H2 }\end{array}$} & \multirow{2}{*}{$\begin{array}{l}\begin{array}{l}\text { Internal quality of } \\
\text { the model }\end{array} \\
\text { Mean F2 }\end{array}$} \\
\hline & & & & & & \\
\hline Image & 4.2588 & 0.9455 & & & 0.7764 & \\
\hline Expectations & 3.7193 & 0.9666 & 0.822 & 0.863 & $0.906 \mathrm{I}$ & 0.7448 \\
\hline Quality perceived & 3.9776 & 0.9675 & 0.8406 & 0.814 & 0.7885 & 0.6628 \\
\hline Value perceived & 3.8095 & 0.9815 & 0.7952 & 0.875 & 0.9637 & 0.7664 \\
\hline Satisfaction & 3.7251 & 0.9667 & $0.894 I$ & 0.9 & 0.9065 & 0.8112 \\
\hline Claims & 3.9837 & 0.8883 & 0.5776 & 0.68 & 0.7996 & 0.4618 \\
\hline Loyalty & 3.5723 & 0.9361 & 0.8372 & 0.858 & 0.8799 & 0.7378 \\
\hline Mean & & & 0.7948 & 0.815 & 0.8366 & 0.6975 \\
\hline
\end{tabular}

$\mathrm{R}^{2}$, coefficient of determination; $\mathrm{H}^{2}$, measure of commonality; $\mathrm{F}^{2}$, redundancy measure; GoF, index of goodness of fit.

Source: own elaboration based on the results obtained in the study

\section{Discussion}

The present study, implemented in December 2016, considered the evaluation of 262 users of the health service of the School of Arms. In this sample, it was determined a mean index of the users global satisfaction of 6.8 values. This result was obtained with $95 \%$ certainty, type I error probability of 0.0000 (high statistical significance) and reduced variances of the respective latent variables $(0.0507 ; 0.0623$; 0.0447). According to Likert's scale interpretation, these results point to a high perception of user satisfaction perceived by the use of health services at the School of Arms. ${ }^{23}$ The aforementioned data seem to follow the trend observed in the Portuguese national health system, in which most of the users reported a level of satisfaction between 6 and $7 .{ }^{26}$ These results are also in agreement with those obtained in health services of schools of Israeli defence forces in which more than $60 \%$ of the subjects obtained high levels of satisfaction. ${ }^{27}$ However, the index reached in the School of Arms is higher than that obtained in the external consultations of the Armed Forces Hospital - Polo de Lisboa, whose responses were concentrated between 4 and 6 values. ${ }^{28}$

There is also evidence of a lower claims rate and loyalty values higher than most published national data. ${ }^{16,28}$ The results obtained at the end of the study also make it possible to identify the indicators that are most likely to be satisfied by the users evaluation. Stands out "the contribution of the health unit to society" (7.82), the "quality of the services provided taking into account access to them is free" (7.59), and "the attention paid to users" (7.45). It is possible as well to point out the indicators that have obtained less satisfactory results from the perspective of the users for the services enjoyed. Is highlighted the "accessibility to health unit services through new technologies" (6.13), the "innovation and focus on the future by the health unit" (6.30), the "evaluation of the health unit with the ideal health unit for the users" (6.37), and the "diversity of services offered by the unit" (6.39). These data seem to reveal that, in general, the price-quality relationship offered by the health unit is quite satisfactory for these users. However they would like to improve its accessibility through technological means, they would like the unit to have a medium-long focus term and are interested in diversifying the offer of services currently available.

Therefore, this information suggests a convergence between the requirements of the users and the recommendations of the scientific evidence for health services. Above all, as regards the introduction of innovation in order to facilitate access to services, the diversification of health services provided, and the definition of long-term strategic plans. ${ }^{29-33}$ For these purposes greater involvement of users in the identification and prioritization of the needs and innovations to be introduced ${ }^{29-33} \mathrm{As}$ for the analysis of the adjustment quality and 
prediction capacity of the model, with a maximum error of $5 \%$, the results suggest robustness, stability and parsimoniousness. ${ }^{23,34}$ The proposed model presents a high goodness index of the adjustment $(\mathrm{GoF}=0.815)$, which means that the discrepancy between the structural matrix of the theoretical data and that of the observed results is a maximum of $18.5 \%{ }^{23,34}$ The sample size was considered quite adequate, allowing the model to explain about $83.7 \%$ of the observations (mean of the mean $\mathrm{H}^{2}=0.8366$ ) and a high degree of representation for the generality of the observed variables (adjusted $\mathrm{R}^{2}>0.3$ and $\left.<0.9\right){ }^{23,34}$ The exception occurred at the level of the variables that fall within the "complaints" dimension (57.7\%), which are still values that show a median capacity for explaining the results. ${ }^{23,34}$ It was also found that the effect size of the latent variables in the explanation of another latent variable was equally high (mean $\mathrm{F}^{2}>0.35$ for all blocks and mean of the mean $\mathrm{F}^{2}=0.6975$ ).

Furthermore, a statistically significant coefficient (p-value $<0.000)$ between all the studied relationships (H1, H3, H5, H7, H7, H8, H9, H10, H11 and H12 with Proba $>|\mathrm{T}|=0.000)$, except for the "image" on "satisfaction" (H2) and of the "expectations" in the "perceived value" (H4). ${ }^{23,34}$ The above results for the quality and performance evaluation of the model proposed by Fornell et al., ${ }^{12}$ in general, are consistent with the high performance results detected in other studies, ${ }^{12,13,35,36}$ and more recently Vaz et al.. ${ }^{31}$ This coherence of results contributes to reinforce the validity of the underlying assumptions, as well as the explanatory capacity of construct of the model proposed. ${ }^{23,34}$ The observed exceptions concern the influence of "image" on "satisfaction" (H2), whose impact was not significant, contrary to data from previous investigations, namely those developed by Ciavolino et al.,., ${ }^{1435,36}$ and Vaz et al.. ${ }^{31}$ In the latter, the "image" was of the variables with the most relevant influence on satisfaction. ${ }^{31}$

Also, the "expectations" in the present study did not reveal a significant effect on the "perceived value" (H4), in comparison with that found in higher education in Uruguay. ${ }^{31}$ However, these results disagree with the data obtained in the study by Ciavolino et al., ${ }^{35}$ the results of the research carried out by Lopes et al., ${ }^{13}$ and are also contrary to observation in Portuguese higher education. ${ }^{31}$ This also means that the direct determinants of user satisfaction at the School of Arms seem to point to "expectations", "perceived quality" and "perceived value", thus differentiating in part from other contexts. In the field of higher education, the data imply that the "image", "expectations", "perceived quality" and "perceived value" are direct determinants of satisfaction. ${ }^{31}$, While in the Uruguayan higher education ${ }^{31}$ and telecommunications services in Spain, ${ }^{36}$ it is suggested that direct determinants of satisfaction are "image", "perceived quality", "perceived value". In Sweden, in a study that considered several areas of the industry, it was observed that in a general way the satisfaction of customers depends directly on the "image", "expectations", "perceived value" but also on new variables incorporated in the model as "hardware" and "software". ${ }^{35}$ This suggests that new variables, possibly differentiating between contexts, may play an important role in the representation of global customer satisfaction and therefore are aspects that customers take into account when they evaluate the satisfaction of the services that they enjoyed.

\section{Conclusion}

The present study obtained indications that with the present resources, functional structure and interaction offered by the School of Arms, correspond with high satisfaction to the needs and values of its users. ${ }^{23}$ The results of the study also seem to point to a model of the global satisfaction of the users in the health service of the School of Arms, robust and globally valid. ${ }^{23,34}$ Therefore, it can eventually be used as an administrative monitoring tool for the performance of military health services in terms of the level of satisfaction of its users. However, the differences detected between the results of the present study and the investigations, especially with regard to determinants with greater and significant weight on satisfaction, seems to suggest that users value different dimensions in relation to different services they enjoy which contradicts the idea that the model does not require adaptations, ${ }^{16}$ and, conversely, it may have to be adjusted in the context of implementation, not only to remove some dimensions but also to consider others with possible weight in the assessment of users satisfaction. More studies are therefore necessary, both with regard to the study of other variables with significant weight in the context under study but also to implement the proposed model in a greater variety of public service areas. In the military context studies are recommended in different health services, since the military context can be diverse, as to the type of services available, procedures, human, physical and material resources, which according to several researchers can condition the perception of satisfaction of users. ${ }^{7,9,20,21}$

It is also considered important that future studies contemplate the relations of influence in the opposite sense to those described in the initial model, more specifically in relation to the relationship between "image" and "satisfaction" and also of "expectations" and "perceived value" since the meaning assumed in the initial model was not found to be in doubt whether, in the context of military services, the influence relation between these variables occurs in the opposite direction. It is also recognized that the effects observed in the present study were not unbiased to bias, highlighting the constraints inherent in the sampling process. ${ }^{23}$ As such, studies are recommended in other Portuguese military services that, like the present study, evaluate the global satisfaction index of the users according to the model of Fornell et al..$^{12,16}$ but using a random sampling process..$^{23,37,38}$ Finally, it is concluded that, in general, the results of the present study are innovative in the context of military health services in Portugal, they represent a contribution to the evaluation of the performance of military health services according to a user-centered approach and for understanding the overall model of the underlying satisfaction.

\section{Acknowledgements}

None.

\section{Conflict of interest}

The author declares that there is no conflict of interest.

\section{References}

1. Comissão Europeia. Quality of Public Administration-a Toolbox for Practitioners. Comissão Europeia. Luxamburgo: Publications Office of the European Union. 2015.

2. Correia P. Ministério Público n.0-Sobre como Institucionalizar uma Mentalidade Orientada para a Qualidade. Trabalho apresentado em X Congresso do Ministério Público, In: Qualidade na Justiça, Qualidade da Democracia, editors. Vilamoura. 2015;116-140.

3. Bilhim J, Correia P. Diferenças nas perceções dos valores organizacionais dos candidatos a cargos de direção superior na Administração Central do Estado. Sociologia, Revista da Faculdade de Letras da Universidade do Porto, 2016;XXXI:81-105. 
4. Correia P. O impacto do Sistema Integrado de Gestão e Avaliação do Desempenho da Administração Pública (SIADAP) na satisfação dos colaboradores-O caso dos serviços do Ministério da Justiça em Portugal. Tese de Doutoramento em Ciências Sociais (Especialidade em Administração Pública), Lisboa, Instituto Superior de Ciências Sociais e Políticas da Universidade Técnica de Lisboa. 2012.

5. Andrews M. Good Government means different things in different countries. Governance. 2010;23(1):7-35.

6. Hårsman B, Quigley J. Political and public acceptability of congestion pricing: ideology and self-interest. Journal of Policy Analysis and Management. 2010;29:854-874.

7. Liu S, Amendah E, Chang EC, et al. Satisfaction and Value: A MetaAnalysis in the Healthcare Context. Health Marketing Quarterly. 2006;23(4):49-73.

8. Mohd A, Chakravarty A. Patient satisfaction with services of the outpatient department. Med J Armed Forces India. 2014;70(3): 237-242.

9. US Department of Defense. Publications. Acquired on 8 of the 1 of 2017. 2014.

10. Larivière B, Keiningham T, Aksoy L, et al. Modeling Heterogeneity in the Satisfaction, Loyalty Intention, and Shareholder Value Linkage: A Cross-Industry Analysis at the Customer and Firm Levels. Journal of Marketing Research. 2016;LIII:91-109.

11. Wensing M, Vedsted P, Kersnik J, et al. Patient satisfaction with availability of general practice: an international comparison. Int J Qual Health Care. 2002;14(2):111-118.

12. Fornell C, Johnson M, Anderson E, et al. The American Customer Satisfaction Index: Nature, Purpose and Findings. Journal of Marketing. 1996;60(4):7-18.

13. Lopes H, Pereira C, Vieira A. Comparação entre os modelos Norte Americano (ACSI) e Europeu (ECSI) de satisfação do cliente: um estudo no setor de serviços. Revista de Administração Mackenzie. 2009;10(1):161-186.

14. ECSI Portugal. Divulgação de resultados ECSI 2016 , metodologia e modelo. Acquired on 13 of the 12 of 2016, at ECSI PORTUGAL - Índice Nacional de satisfação do Cliente: 2016.

15. Calvo-Porral C, Lévy-Mangin JP. Smooth operators? Drivers of customer satisfaction and switching behavior in virtual and traditional mobile services. Revista Española de Investigación. 2015;19(2):124-138.

16. ECSI Portugal. ECSI PORTUGAL - Índice nacional de satisfação do cliente. Acquired on 30 of the 12 of 2016, at Divulgação de Resultados: 2016.

17. Hurst J. Effective Ways to Realise Policy Reforms in Health Systems. (51). (O. Publishing, Ed.) Paris: OECD Health Working Papers. Acquired on 12 of the 12 of 2016,2010 .

18. Revilla-Camachoa MÁ, Cossío-Silvaa FJ, Palacios-Florencio B. Corporate Responsibility under the ECSI model: An application in the hotel sector. European Research on Management and Business Economics. 2017;23(1):23-32.

19. Ferreira I, Cabral J, Saraiva P. An integrated framework based on the ECSI approach to link mould customers' satisfaction and product design. Total Quality Management \& Business Excellence. 2010;21:1383-1401.

20. Murdie A. Putting conflict where it belongs: a response to "creating shared responsibility through respect for military culture: the russian and american cases". Public Administration Review. 2011;530-534.
21. Goel RK, Saunoris JW. Military versus non-military government spending and the shadow economy. Economic Systems. 2014;38(3):350359.

22. Fathalla MF. A Practical Guide for Health Research. Acquired on 1 of the 1 of 2017, at World Health Organization. 2004.

23. Ramineni V, Rajendra G, Phaneendra K. Estimation of casual relationships among the data items by using statistical data mining techniques. International Journal of Advanced Computer and Mathematical Science. 2012;3(2):2230-9624.

24. Marôco J. Análise estatística com o SPSS statistics. Pêro Pinheiro, Lisboa: Report Number. 2014.

25. Schumacker R, Lomax R. A Beginner's Guide to Structural Equation Modeling. 3rd ed. T \& Group, Editor. New York: Routledge. 2010.

26. Bleich SN, Özaltin E, Murray CJ. Bulletin of the World Health Organization. Acquired on 12 of the 1 of 2017, at World Health Organization: 2009.

27. Zimlichman E, Afek A, Mandel D, et al. Army personnel in different settings of primary health care clinics. Military Medicine. 2004;169(5):365-388.

28. Ferrão HM. Avaliação de Indicadores de Qualidade no Hospital das Forças Armadas. Instituto Universitário Militar, Departamento de Estudos Pós-Graduados, Pedrouços. 2016.

29. Feijão A, Santos A, Vasconcelos A, et al. eHealth em Portugal: visão 2020. ThinkTank. 2015.

30. Institute of Customer Service. instituteofcustomerservice.com. Acquired on 10 of the 1 of 2017 , at UKCSI: The state of customer satisfaction in the UK.

31. Vaz R, Freira D, Vernazza E, et al. Can students' satisfaction indexes be applied the same way in different countries? Int Rev Public Nonprofit Mark. 2016;13(2):101-118.

32. World Health Organization. Financiamento dos sistemas de saúde: o caminho para a cobertura universal. Geneva: WHO; 2010.

33. World Health Organization. Contributing to social and economic development: sustainable action across sectors to improve health and health equity (follow-up of the 8th Global Conference on Health Promotion). Sixty-eighth world health assembly (pp. 1-20). WHO: Report of the Secretariat. 2015.

34. Xiong B, Skitmore M, Xia B. A critical review of structural equation modeling applications in construction research. Automation in Construction. 2015;49:59-70.

35. Ciavolino E, Dahlgaard JJ. ECSI - Customer Satisfaction Modelling and Analysis: A Case Study. Total Quality Management. 2007;18:545-554.

36. Gijón C, Garín-Muñoz T, Pérez-Amaral T, et al. Satisfaction of individual mobile phone users in Spain. Telecommunications Policy. 2013;37(10):940-954.

37. Administração Central do Sistema de Saúde. Sistema de avaliação da qualidade apercebida e da satisfação do utente dos hospitais EPE e SPA. Resultados Globais de 2008. Lisboa: Universidade Nova ISEGI. 2008.

38. Yanova N. Assessment of satisfaction with the quality of education: customer satisfaction index. Procedia - Social and Behavioral Sciences. 2015;182:566-573. 